\title{
Mesocarnivore Distribution along Gradients of Anthropogenic Disturbance in Mediterranean Landscapes
}

\author{
Ignasi Torre ${ }^{1 *}$, Tomàs Pulido² ${ }^{2}$ Marc Vilella² ${ }^{2}$ and Mario Díaz ${ }^{3}$
}

1 BiBio Research Group, Natural Sciences Museum of Granollers, c/ Francesc Macià 51, E-08402 Granollers (Barcelona), Spain.

2 Natural Sciences Museum of Granollers, c/ Francesc Macià 51, E-08402 Granollers (Barcelona), Spain.

3 Department of Biogeography and Global Change, National Museum of Natural Sciences, CSIC, C/Serrano 115 bis, E-28006 Madrid (Spain); orcid: 0000-0002-6384-6674

* Corresponding author: itorre@mcng.cat; orcid: 0000-0002-4803-9524

\begin{abstract}
Wildfires are important sources of landscape change in Mediterranean environments, creating large patches of natural habitats (i.e., scrublands) inside protected areas, whereas woodland patches remained at the border in the vicinity of human settlements. Landscape patterns resulting from these gradients influence habitat suitability for mesocarnivores regarding food and shelter. In winter and summer 2019, we sampled 16 independent line-transects of four camera traps each (for a total of 64 cameras), covering the main habitats of the study area (woodlands, scrublands, and crops). Cameras were baited to compensate for low detectability of target species, and mesocarnivore contacts were analyzed by means of GLMMs and occupancy models. We hypothesized that Mediterranean mesocarnivores were constrained by two opposing forces, pushing them living in semi-natural but highly fragmented and heterogeneous landscapes created by humans, or living in natural but less suitable and continuous habitats created by fire regimes. In the former case, mesocarnivores will find protection against predators and resting sites in forests, as well as improved food opportunities in crops and urban areas, despite the possible interference with humans and their pets. Potential cascading effects linked to ecological roles of Mediterranean mesocarnivores on the succession of Mediterranean landscapes would imply longer-term effects of human disturbance on landscape trends.
\end{abstract}

Keywords: Carnivores; Habitat suitability; Landscape gradients; Scrublands; Woodlands; Wildfires.

\section{Introduction}

Responses of predators to global change may have cascading effects on prey communities well beyond direct effects of global change drivers on prey [1]. For instance, direct interactions between humans and large carnivores, in the form of persecution and extermination of the top predators competing with human interests, tend to favour the expansion of mesocarnivores (mesopredator release hypothesis) [2]. Direct numeric effects on prey are usually stronger for mesocarnivores than for top predators, due to more generalist diets and habitat requirements of the former [3]. Indirect effects mediated by fear may be stronger than numeric effects [4][5], sometimes even cascading down to plant populations by decreasing herbivory or increasing mutualistic interactions such as seed dispersal [6]. Despite their key influence on communities, fewer work has been done on mesocarnivore response to global change as compared to more charismatic top predators [7][8].

Despite mesocarnivores were persecuted and sometimes harvested as fur-bearers [9], most species are protected today, at least in Europe, as top predators are. Generalist patterns of habitat use and slower recovery of top predators have usually led to a rapid recovery of mesocarnivores, being considered as good models to analyze the effects of land use changes in anthropic environments [10]. However, owing to their relatively large territory size, they rely more on landscape-scale patterns to define their distribution range rather than on local habitat features, more influent in smaller animals. In the Iberian Peninsula, mesocarnivores generally benefit from heterogeneous mosaics of arable fields and semi-natural habitats such as forests and scrublands [11]. These landscapes are usually found surrounding protected areas, where fire suppression strategies and limits to human intervention provide the large patches of semi-natural habitat needed by most mesocarnivores [12]. 
The importance of protected areas is expected to decrease in the Mediterranean basin due to land abandonment by the cessation of agriculture and traditional land-uses [13]. Such abandonment promotes the natural regeneration and re-establishment of native habitats (i.e., expansion and connectivity of woodlands) [14], but also an increase of fire recurrence and surface burned [15], which affects landscape composition and structure giving rise to large patches of scrub [16]. Mediterranean mesocarnivore recovery, and its cascading effects, are thus constrained by two opposing forces, human land uses (pushing carnivores to live in semi-natural but highly fragmented and heterogeneous landscapes) and abandonment and increased fire effects (pushing them to live in more continuous seminatural habitat of lower quality created by fire regimes).

Here we analyze patterns of distribution of mesocarnivores along the gradients of anthropogenic disturbance found in Mediterranean landscapes and discuss the potential cascading effects of these patterns on the long-term trajectories of these landscapes [16]. Our aim is predicting responses of Mediterranean systems to global change beyond current simplistic niche modelling approaches [1]. We predicted that responses of mesocarnivores along these anthropogenic gradients will depend on the perceived suitability of such gradients by the target species. Mesocarnivore abundance will increase along landscape gradients offering higher availability of refuges (against predators and climate) and food opportunities, such as woodland patches within mostly deforested anthropogenic landscapes [17], rather than along more natural and homogeneous landscapes within protected areas, dominated by fire-prone scrub. If this was true, key ecological functions of Mediterranean carnivores would be more associated to human influence than to natural succession.

\section{Materials and Methods}

\subsection{Study area and sampling design}

The study area includes two protected areas (Garraf and Foix Natural parks) covering 15,000 ha in the Litoral Range of Barcelona province, NE Spain (Figure 1). The landscape was modelled by human activities (forest management, cattle grazing, crops) for centuries, but those activities were abandoned during the last decades. Natural shrub encroachment and afforestation is linked to increased fire recurrence, with two large recent wildfires burning 10,000 ha (1982) and 4,300 ha (1994) [18]. The natural vegetation consists of coastal maquis of Quercus coccifera and Chamaerops humilis and coastal holm oak Q. ilex forests, which are dominated by fire-adapted plant species (Q. coccifera, Q. ilex, Arbutus unedo, Pistacia lentiscus) and species with enhanced post-fire germination after fire (Pinus halepensis and Cistus spp.). Garraf's land uses are dominated by shrublands and grasslands $(80 \%)$, followed by woodlands $(15 \%)$, and small patches of crops $(2 \%)$ and urban areas (3\%). Shrublands and grasslands are also dominant in Foix $(65 \%)$, but crops are the second land-use (20\%), followed by woodland (11\%) and urban areas (4\%)[19].

We set 16 line transects $750 \mathrm{~m}$ long, placing in each transect four cameras separated $250 \mathrm{~m}$ and two cameras situated at both extremes of the lines $(0$ and $750 \mathrm{~m})$. Line transects were separated at least $1 \mathrm{~km}$ among them and were established with the aim of covering the variety of habitats present (pinewoods, scrublands, and crops), in order to analyse mesocarnivore responses to habitat structure and landscape composition [12]. We selected six woodlands (mature and young pinewoods and holm oak woodlands), six scrublands at different stages of secondary succession (burned in 1994 or before), and four crops (cereal crops and vineyards). Transects were sampled in winter (4th February to 8th March 2019) and summer (23rd July to 16th August 2019). Two camera models were used: 12 Browning cameras (Strike Force HD Pro) and 4 Bushnell cameras (Trophy Cam E3 HD), which were randomly placed in the four transects that were sampled simultaneously. Since camera brand/model may affect detection probabilities [20], we made sure camera settings were 
similar for the two models. Within every location selected, cameras were placed in areas devoid of thick vegetation to facilitate animal detection. All cameras were placed at least three hours before sunset and worked during four consecutive nights then removed $[21,22]$. Sampling was performed in working days to avoid the effect of visitors (and their pets) during weekends. Within every transect, we baited two cameras with sardines in olive oil [23,24], alternating position with the other two cameras, which were not baited (controls). We alternated baiting positions between the two seasonal sampling sessions. The design was set to reduce the sampling effort necessary to detect mesocarnivore species when present, as well as to analyse and control for bias associated to baiting [20,25].

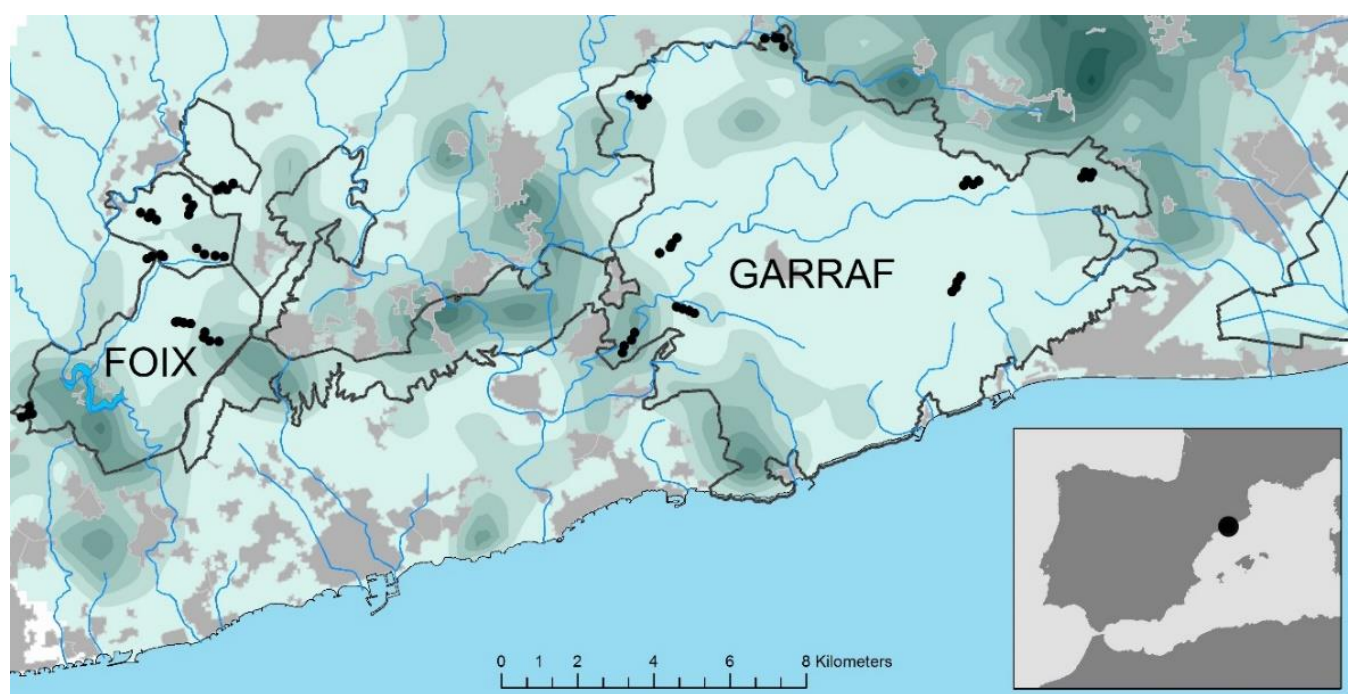

Figure 1. Situation of the 16 line-transects (four cameras each, black dots) in the Natural parks of Garraf and Foix, Catalonia (NE Spain). Green dark isoclines indicate forest cover, and light grey urban areas.

\subsection{Statistical analyses}

Habitats around line transects were described using a land-use database with environmental information available for $1 \mathrm{~km} \times 1 \mathrm{~km}$ UTM squares. Each transect was characterized with data from the central UTM square where it was located and the eight squares surrounding it, thus considering an area of $9 \mathrm{~km}^{2}$ [26-28]. A Principal Component Analysis (PCA) was performed on four main land-use categories (forests, scrublands, crops, and urban) to convert a set of correlated variables into a set of values of linearly uncorrelated variables called principal components [29]. Principal components with eigenvalues $>1$ (Kaiser criterion) were retained to interpret habitat gradients with ecological meaning and were then used as predictors in further analyses. Habitat heterogeneity was calculated as the Shannon Diversity Index of the four main land-use categories.

Captures were considered as independent events (i.e. contacts) when pictures of the same species were taken more than 30 minutes apart [20]. The targeted mesocarnivore species were red foxes Vulpes vulpes (Linnaeus, 1758), domestic dogs Canis lupus familiaris (Linnaeus, 1758), stone martens Martes foina (Erxleben, 1777), European badgers Meles meles (Linnaeus, 1758), weasels Mustela nivalis (Linnaeus, 1758), genets Genetta genetta (Linnaeus, 1758), and feral cats Felis silvestris catus (Schreber, 1777).

Generalized linear mixed models (GLMMs) were fitted to two types of response variables: number of contacts, and species richness/density. The former was calculated for seven different groups or species: red fox, stone marten, badger, genet, the total of these four wild mesocarnivore species, domestic dog and feral cat; the second was calculated for wild species. Both number of contacts and species richness were assumed to follow a Poisson error distribution [30]. On the other hand, the six species were also modelled with 
binomial error distribution (presence-absence), thus assessing the potential effect of counting the same individual more than once (pseudo-replication), as individuals were not identified due to the absence of distinctive fur marks in most of the species. We considered the same four explanatory variables for all modelling processes: season and bait as fixed factors with two levels each (winter or summer, and with or without) and the two first principal components that summarized land cover data. Two-level interactions among these four variables were also included, resulting in six different combinations. Camera position nested in line transect was included as a random factor to account for un-controlled variables associated to camera locations. For each response variable, the $R$ functions dredge and glmer were used to build models with all possible combinations of explanatory variables. According to the principle of parsimony and our sample size $(\mathrm{n}=$ 127 observations), we selected models with $\triangle \mathrm{AICc}<2$ as meaningful. For the selected models, we calculated pseudo- $\mathrm{R}^{2}$ values [31] by means of the $\mathrm{R}$ function r.squaredGLMM and the delta method for variance estimation and we eventually showed the one with the highest conditional pseudo- $\mathrm{R}^{2}$. Overdispersion issues of the response variables were assessed by calculating the scaled deviance of their most parameterized model and checking whether it followed a Chi ${ }^{2}$ distribution with the residual degrees of freedom (114). Species models showing dispersion irregularities (scaled deviance $<0.5$ or $>1.5$ ) were eventually built with negative binomial as link function ( $\mathrm{R}$ function glmer.nb), but results were rather similar (not shown). R-functions used were available in the packages MuMIn [32] and lme4 [33].

Common and widely distributed Mediterranean mesocarnivores -such as genets and badgers- might show very low detectabilities in camera trapping studies [24]. Probability of detection (or detectability, $p$ ) can be defined as the probability of detecting a species when actually present and can be considered as a nuisance parameter derived from sampling issues [34]. Since low detection probabilities $(p<0.3)$ [35] can be responsible of underestimates of occupancy due to false negatives (non-detection of the species when present), we used Multiple-season Occupancy models to ascertain actual occupancy under an imperfect detectability framework [34]. Detection histories were built for every seasonal survey and transect, considering each night as a sampling occasion -to account for temporal variation- and whether cameras were baited or not. Histories consisted in a series of detection (1) and non-detection (0) data, owing that the species was always detected when present. We fitted competing occupancy models (software PRESENCE)[36] to determine the parameters mostly affecting occupancy $(\psi)$ and detectability $(p)$, once controlling for imperfect detection. We started with a null model, considering that probability of occupancy did not change between consecutive sampling occasions and between transects, and setting detection probabilities also constant $\psi(\cdot) \mathrm{p}(\cdot)$. In a second step, detection probabilities were modelled while setting occupancy constant [37], exploring the two main sources of variability: $\operatorname{bait}(b)$ and time $(t)$, but without interactions [20]. The best model selected (according to AIC) was retained and further analyzed by including sources of variability for the probability of occupancy: landscape composition summarized by two PCs $\psi(p c 1)$ and $\psi(p c 2)$ as site-dependent covariates. We also built cumulative detectability curves to compare the sampling effort necessary to detect the four wild species and calculated the number of sampling occasions with sequential non-detections necessary to ascertain a species was absent with $95 \%$ of certainty in baited/non-baited stations [20]. 


\section{Results}

PCA yielded two significant factors, explaining altogether the $98 \%$ of total variance of land-use categories. The first (PC1) explained most of the variance (79\%) and was interpreted as a gradient from crops to scrublands. The second (PC2) explained the $19 \%$ of variance and was interpreted as a gradient from crops to woodlands. Dominant scrublands were negatively correlated with the other land-uses, especially with crops $(r=-0.79$, $\mathrm{p}<0.001)$, but also with forests $(r=-0.50, \mathrm{p}<0.05)$, and urban areas $(r=-0.47, \mathrm{p}<0.07)$. Scrublands (and PC1) showed a strong negative correlation with heterogeneity $\left(\mathrm{H}^{\prime}: r=-\right.$ $0.93, p<0.0001)$, suggesting that these areas -mostly situated in the center of the study area- were very homogeneous. Landscape heterogeneity increased towards the borders of the parks (Figure 1), where a mosaic formed by natural habitats (forests patches and scrublands) were combined with villages and crops.

We obtained 177 independent contacts of wild and 88 of domestic mesocarnivores in 512 camera-nights (27.6\% of total mammal contacts). Red foxes were the most frequent species (18.4 contacts per 100 camera-nights), followed by stone martens (8.8), badgers (4.9), genets (2.1), and weasels (0.4). Baited stations increased the number of total contacts (75 contacts $\times 100$ camera-nights) when compared with non-baited stations (28.5 contacts $\times 100$ camera-nights).

Most detections of wild carnivores occurred during the second night of camera exposure and dropped during the fourth night (Figure 2). Naïve occupancy was affected by using baits, increasing in all the species with reference to non-baited cameras. A Log-Linear model showed that mesocarnivore detections were distributed similarly among species along the four days of camera exposure in baited/non-baited cameras (Species x Bait $\mathrm{x}$ Day: $\left.\mathrm{ML}^{-C h i}{ }^{2}=3.0, \mathrm{df}=9, \mathrm{p}=0.96\right)$. Nonetheless, total contacts changed along the four days of camera exposure, the second day showing the highest number of detections $\left(\mathrm{Chi}^{2}\right.$ $=86.6, \mathrm{df}=28, \mathrm{p}<0.0001$, Figure 2).

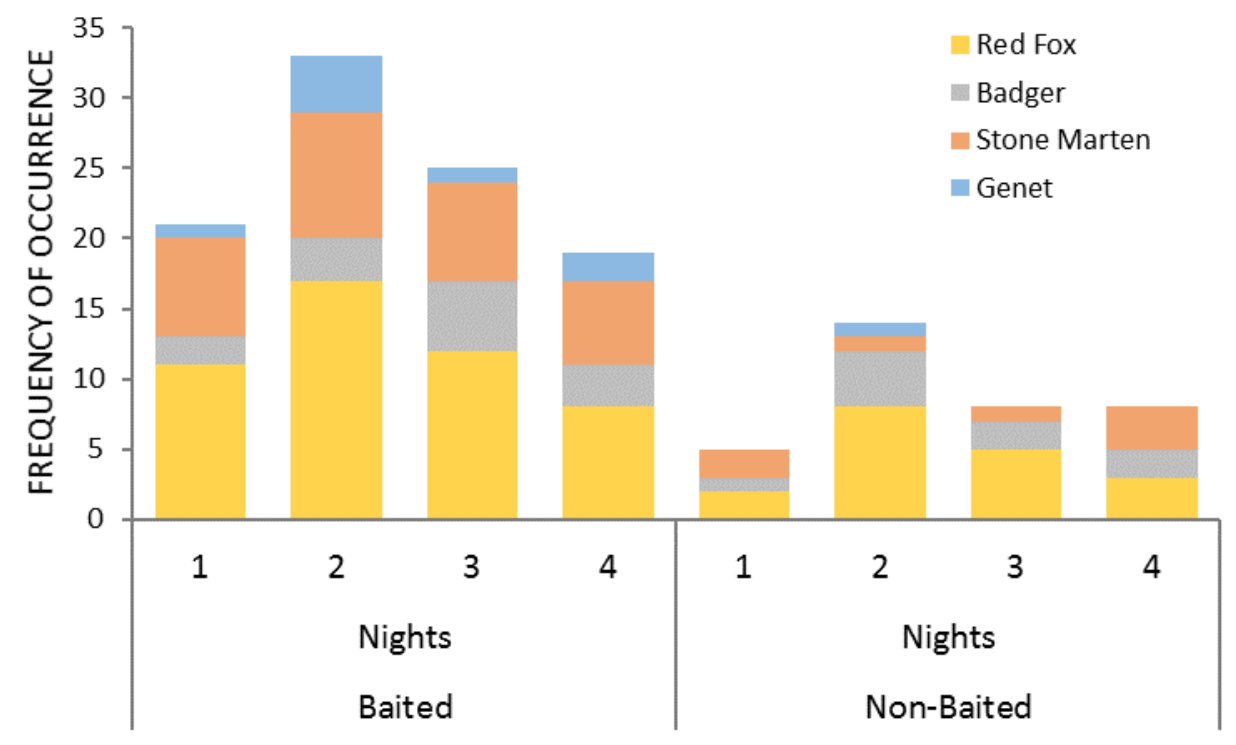

Figure 2. Frequency of occurrence (independent contacts) of wild mesocarnivores along the four nights of camera exposure in baited and non-baited stations.

Regarding the number of contacts and richness, GLMMs with Poisson error fitted well the data in the case of the red fox and total wild contacts, as well as species richness. A negative binomial distribution fitted better in the case of the cat and the stone marten, but genets, badgers, and dogs, did not fit optimally with either Poisson or negative binomial distributions. Furthermore, the use of negative binomial did not reduce dispersion issues 
in any case, maybe because data was mostly under-dispersed (variance $<$ mean). Therefore, the models - only Poisson models shown- should be interpreted with caution in the case of severe under-dispersion. Binomial models (presence/absence) yielded almost the same results (not shown). Results highlighted the positive influence of bait in six out of eight response variables, displaying higher efficiency during summer (Table 1). Baited stations showed more contacts for all species but badger and cat. They also reported a larger number of total wild contacts and a higher species richness than un-baited stations. PC1 and PC2 positively influenced the total number of contacts and richness of wild species, being the latter especially determinant in stone marten, dog and cat. Both PCs represented landscapes gradients from crops to scrublands (PC1) and from crops to forests (PC2), suggesting that natural habitats favoured mesocarnivore communities. In general, contacts increased in winter, while the use of bait seemed to be less determinant in that season.

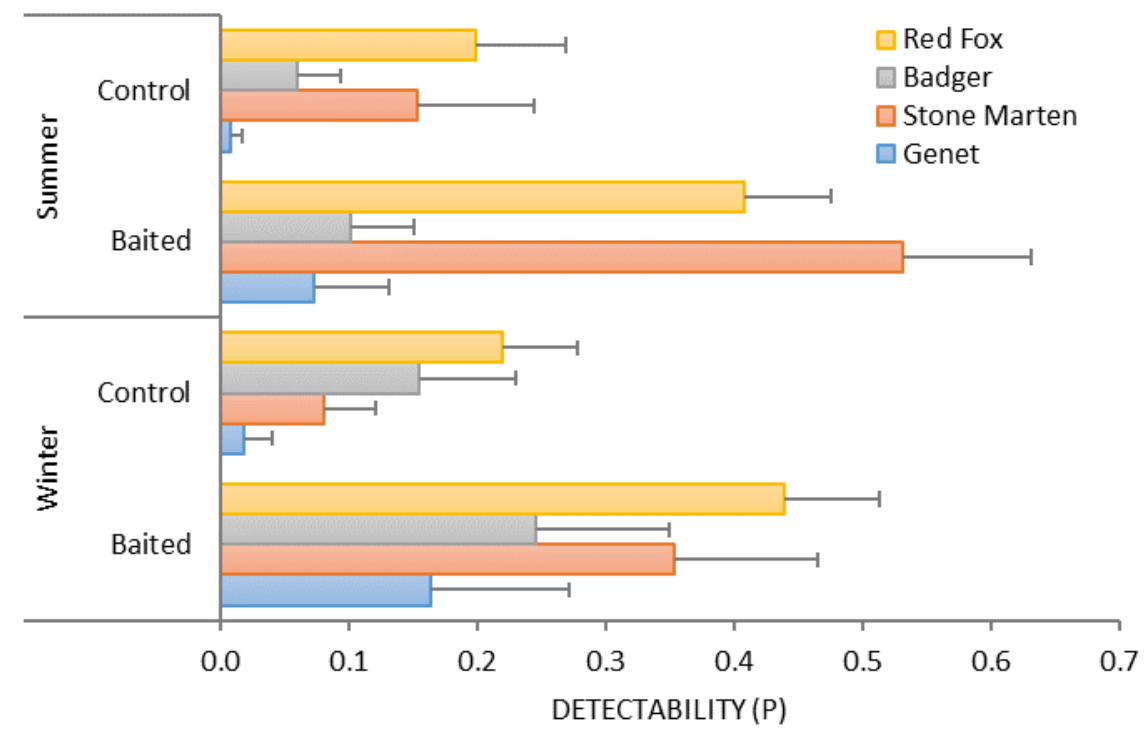

Figure 3. Seasonal modelled probability of detection (detectability, $p \pm S E$ ) of the four wild mesocarnivore species according to the use of bait in alternated position in camera stations within the 16 line-transects of four cameras each.

Multi-season occupancy models fitted to detection histories revealed that all mesocarnivores increased observed values of occupancy once imperfect species probability of detection was considered. In fact, genets increased almost four times actual occupancy, it was doubled in the case of badgers, and showed lower increases both in martens and foxes. In un-baited cameras, the four wild mesocarnivores had low detectabilities $(p<0.3)$, especially the genet ( $p<0.02$, Figure 3). The use of baits increased the probability of detection, and the occupancy models highlighted its influence on species detectability since bait was present in the most parsimonious models for the four species considered (Table S1). This was especially true in the case of genets, as baited cameras improved 9 to 10 times detectability compared to non-baited cameras (Figure 3). Martens ( 4 times more), foxes $(\sim 2)$ and badgers $(\sim 1.6)$ also showed an increase in baited sites. Interestingly, only three consecutive surveys or occasions -on average- would be necessary to be confident of nondetection of any wild species in a baited station, but 21 consecutive surveys would be necessary to be confident of non-detection in non-baited stations (Figure S1). Thus, the use of bait controlled efficiently for the non-occurrence of false negatives during short surveys. Particularly, in the case of genets and stone martens (to a lesser extent) in nonbaited stations, the number of consecutive surveys necessary to control for false absences outnumbered by far the sampling effort performed in this study (63 and 11 consecutive surveys, for genets and martens, respectively). The probability of occupancy of wild 
species was affected by landscape composition gradients (represented by PCs, Table S1, Figure 4). Almost all species increased occupancy towards natural habitats (forests and scrublands), this increase was especially relevant for genets and stone martens along the forest gradient. Both PCs were selected in six out of eight significant models. All models considered valid included bait as a factor affecting detectability.

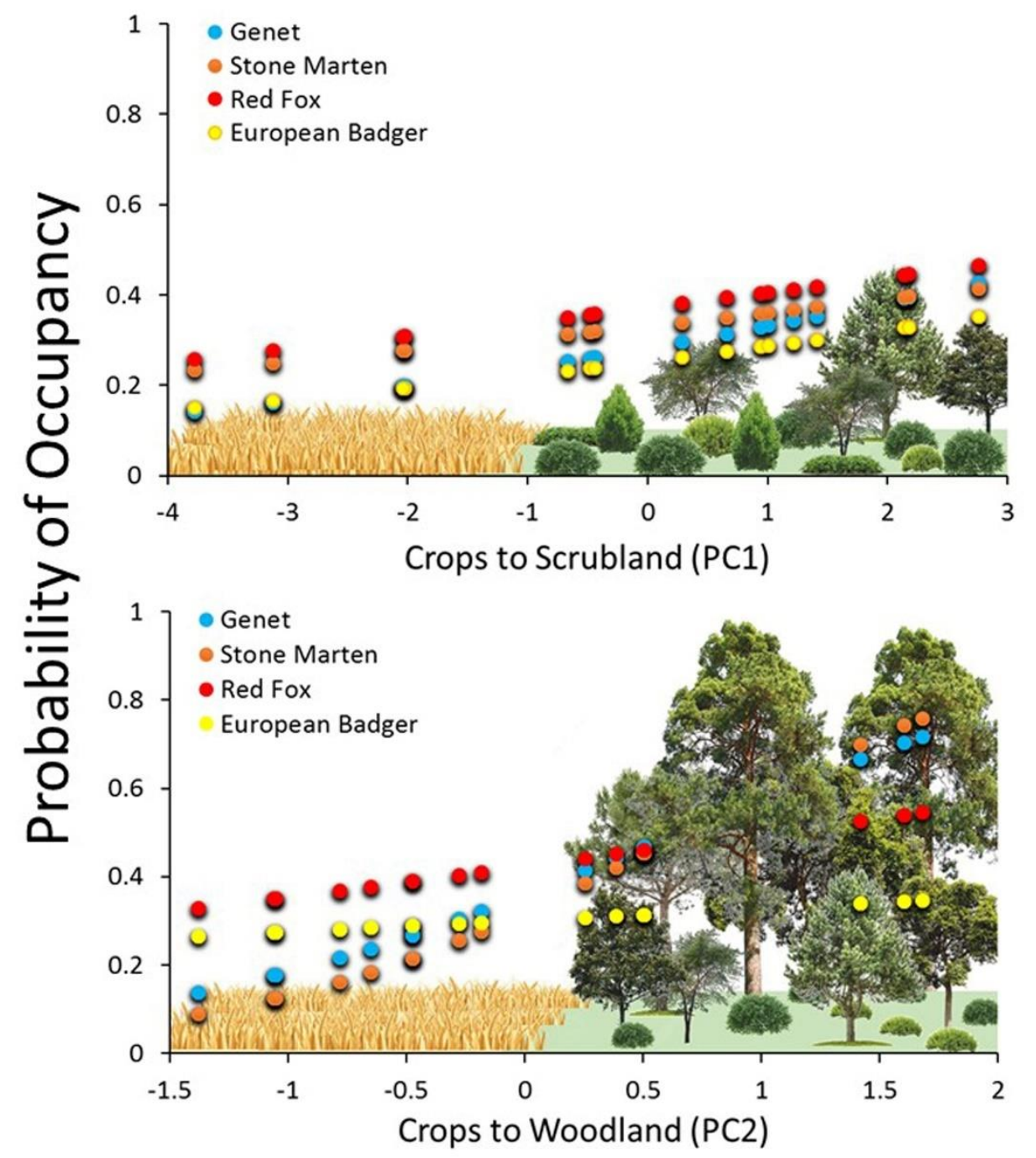

Figure 4. Modelled probability of occupancy of the four wild mesocarnivore species along gradients of landscape composition; PC1: gradient from crops to scrublands (79\% of variance explained); PC2: gradient from crops to forests (19\% of variance explained).

\section{Discussion}

Mediterranean mesocarnivores showed clear-cut responses to landscape change along anthropogenic land-use gradients. The number of species and contacts increased along a gradient from anthropogenic (crops) to natural forested areas [27] and, to a lesser extent, along a gradient from crops to scrublands. Occupancy models yielded similar results, with genets and stone martens showing higher occupancies along the forest than along the scrubland gradient, and red foxes and badgers showing moderate responses to both. Our results generally agreed with predicted and observed broad patterns of habitat use by mesocarnivores in disturbed and fragmented Mediterranean landscapes [11,12,38]. Low detectabilities of all mesocarnivore species [24] in short surveys -such this one- usually precluded interpretations of spatial patterns: here we used an attractant to improve results [22]. We showed that the use of a conventional edible bait (canned sardines)[39] 
was the most relevant factor affecting the probability of detection of all wild mesocarnivores. Un-baited cameras leaded to low detectabilities for the four wild mesocarnivores (especially for the genet $p<0.02$ ), but the use of bait controlled efficiently for the nonoccurrence of false negatives during the survey [20], despite its efficiency decreased during winter [40]. Our procedure allowed obtaining enough data to derive solid interpretations of patterns and minimizing the bias produced by sampling procedures.

Gradients of land use in our study are associated to changes in habitat suitability for mesocarnivores, regarding food and shelter, and provoked significant distributional responses in almost all species. Habitat heterogeneity, created by anthropogenic disturbance within a scrubland landscape structure currently modelled by wildfires, is linked to the positive association of mesocarnivores to a certain degree of afforestation. The landscape studied represented a mosaic of small forest patches surrounded by extensive natural (scrublands) and artificial man-made habitats (crops and urban areas). Forest patches are fragments of natural woodland that remained in the surroundings of the natural parks after the important wildfires occurred during the end of the last century [13]. Fight against fires produced the protection of forests close to urban areas, allowing the persistence of forest patches associated to human settlements. Fire dynamics contributed to create large -but unsuitable- patches of natural habitats (i.e., scrublands) for the generalist mesocarnivores, with woodland habitats remaining at the border of the natural reserves in the vicinity of urban areas. Indeed, in highly deforested landscapes, carnivore activity could be concentrated in the remaining forest fragments (i.e., riverbeds)[17].

Despite other authors suggested the prominent role of scrublands for mesocarnivore conservation [41], our results highlighted that most species showed more preference for forests, which represented a small fraction of the total area available with respect to scrublands (13\% vs. $72 \%)$. The more intense response to forest than to scrubland gradients probably results from the dependence of mesocarnivores on hollows in old trees for resting, which decreases predation risks or thermoregulatory costs [42].

Mediterranean mesocarnivores are thus constrained by two opposing forces, pushing them living in semi-natural but highly fragmented and heterogeneous landscapes created by humans, or living in natural but less suitable and continuous habitats created by fire regimes. In the former case, wild mesocarnivores will find protection against predators and resting sites in forests, as well as improved food opportunities in crops and urban areas. Lack of natural top predators (i.e., wolves Canis lupus) in most of the western Mediterranean communities [43] relaxed the predation pressure on mesocarnivores, and the role of super-predator could be now played by humans [44] and their dogs [45]. Since forest patches near urban areas are widely used for recreation, the presence of human pets (dogs and cats) could produce negative effects to wild mesocarnivores [44,46]. Nevertheless, contacts of red foxes (the most common wild species) were positively associated to dog contacts, and both wild and domestic mesocarnivores responded in a similar way to landscape gradients $(r=0.25, \mathrm{n}=128, p<0.05)$. Wild mesocarnivores living in woody areas can benefit from urbanization [24], for instance, by a reduced amount of hunting pressure near villages, thus enabling proper diurnal rests for mainly nocturnal target species [47]. In fact, the confluence of forests with urban areas could also increase carrying capacities due to food subsidization [48], especially in the case of opportunistic species, such as the red fox (use of rubbish dumps, garbage containers, etc.). Scrublands, on the other hand, offer a higher availability of small mammal prey than woodlands in spring and autumn [49-51], which would benefit species with diets based on small mammals, such as the genet [52]. Less frequency of genets in scrubland patches [4], despite holding higher prey biomass, reinforces the potential role of refuge availability hypothesized above.

Mediterranean mesocarnivores seemed to find better opportunities to thrive in landscape mosaics constituted by woodland patches (providing refuges against climate and 
predators) within a matrix of crops, scrublands and urban areas [53], despite the possible interference with humans and their pets. This scenario implies that the ecological roles of mesocarnivores as predators of small- and medium-sized mammals [49,54,55], and as direct and indirect dispersal agents of keystone Mediterranean plants [56,57], will be concentrated in fragmented forest-urban areas rather than in the more homogeneous and natural landscapes created by wildfires. Consequences of these indirect and interactive responses to global change drivers will be key to understand the long-term effects of global change in Mediterranean ecosystems [16,58].

Supplementary Materials: The following supporting information can be downloaded at: www.mdpi.com/xxx/s1, Table S1. Occupancy models for the wild mesocarnivore species. Only significant models (DeltaAIC <2) are shown, and null models shown for comparison. Figure S1. Cumulative detection probabilities of the four wild mesocarnivores along field surveys (secondary sampling occasions) in baited (dark symbols) and non-baited (open symbols) camera stations. Red fox (circle), stone marten (triangle), genet (square), and badger (diamond).

Author Contributions: Conceptualization, I.T., M.V.; methodology, I.T, M.V., T.P.; software, I.T., M.V.; validation, I.T., T.P., M.V.; formal analysis, I.T. and M.V.; investigation, T.P., M.V.; data curation, M.V., T.P.; writing-original draft preparation, I.T.; writing-review and editing, I.T. and M.D.; visualization, I.T. and M.V.; supervision, I.T., and M.D.; project administration, I.T.; funding acquisition, I.T. All authors have read and agreed to the published version of the manuscript.

Funding: All this research was funded by the Barcelona Provincial Council (Àrea d'Infraestructures i Parcs Naturals, Diputació de Barcelona: ref.no 2018/0013009; 2018/18).

Institutional Review Board Statement: Ethical review and approval were waived for this study.

Data Availability Statement: The data presented in this study are available on request from the corresponding author.

Acknowledgments: Daniel Pons and Emilio Valbuena-Ureña lent us the camera traps and provided all the permissions to perform the field work in the protected areas. To the Park rangers of the Garraf and Foix Natural Parks for their help for finding accessible and representative areas for setting the cameras, and to Joan Pulido and Dolors Escruela for helping during the field surveys.

Conflicts of Interest: The authors declare no conflict of interest. The funders had no role in the design of the study; in the collection, analyses, or interpretation of data; in the writing of the manuscript, or in the decision to publish the results.

\section{References}

1. Díaz, M.; Grim, T.; Markó, G.; Morelli, F.; Ibáñez-Alamo, J.D.; Jokimäki, J.; Kaisanlahti-Jokimäki, M.L.; Tätte, K.; Tryjanowski, P.; Møller, A.P. Effects of climate variation on bird escape distances modulate community responses to global change. Sci. Rep. 2021, 11, 1-9, doi:10.1038/s41598-021-92273-1.

2. Crooks, K.R.; Soulé, M.E. Mesopredator release and avifaunal extinctions in a fragmented system. Nature 1999, 400, 563-566, doi:10.1038/23028.

3. Palomares, F.; Delibes, M.; Revilla, E.; Calzada, J.; Fedriani, J.M. Spatial ecology of Iberian lynx and abundance of European rabbits in southwestern Spain; 2001; Vol. 148;.

4. Diaz, M.; Torre, I.; Peris, A.; Tena, L. Foraging behavior of wood mice as related to presence and activity of genets. J. Mammal. 2005, 86, 1178-1185, doi:10.1644/04-mamm-a-127r1.1.

5. Navarro-Castilla, Á.; Barja, I.; Díaz, M. Foraging, feeding, and physiological stress responses of wild wood mice to increased illumination and common genet cues. Curr. Zool. 2018, 64, 409-417, doi:10.1093/cz/zox048.

6. Gallego, D.; Morán-López, T.; Torre, I.; Navarro-Castilla; Barja, I.; Díaz, M. Context dependence of acorn handling by the Algerian mouse (Mus spretus). Acta Oecologica 2017, 84, 1-7, doi:10.1016/j.actao.2017.07.002.

7. Sergio, F.; Newton, I.; Marchesi, L. Conservation: Top predators and biodiversity. Nature 2005, 436, 192, doi:10.1038/436192a. 
8. Mendoza, M.; Araújo, M.B. Climate shapes mammal community trophic structures and humans simplify them. Nat. Commun. 2019, 10, 1-9, doi:10.1038/s41467-019-12995-9.

9. Roemer, G.W.; Gompper, M.E.; Van Valkenburgh, B. The Ecological Role of the Mammalian Mesocarnivore. Bioscience 2009, 59, 165-173, doi:10.1525/bio.2009.59.2.9.

10. Alexandre, M.; Hipólito, D.; Ferreira, E.; Fonseca, C.; Rosalino, L.M. Humans do matter: determinants of red fox (Vulpes vulpes) presence in a western Mediterranean landscape. Mammal Res. 2020, 65, 203-214, doi:10.1007/s13364-019-00449-y.

11. Curveira-Santos, G.; Marques, T.A.; Björklund, M.; Santos-Reis, M. Mediterranean mesocarnivores in spatially structured managed landscapes: community organisation in time and space. Agric. Ecosyst. Environ. 2017, 237, 280-289, doi:10.1016/j.agee.2016.12.037.

12. Virgós, E.; Tellería, J.L.; Santos, T. A comparison on the response to forest fragmentation by medium-sized Iberian carnivores in central Spain. Biodivers. Conserv. 2002, 11, 1063-1079, doi:10.1023/A:1015856703786.

13. Regos, A.; D'Amen, M.; Titeux, N.; Herrando, S.; Guisan, A.; Brotons, L. Predicting the future effectiveness of protected areas for bird conservation in Mediterranean ecosystems under climate change and novel fire regime scenarios. Divers. Distrib. 2016, doi:10.1111/ddi.12375.

14. Puerta-Pinero, C.; Espelta, J.M.; Sanchez-Humanes, B.; Rodrigo, A.; Coll, L.; Brotons, L. History matters: Previous land use changes determine post-fire vegetation recovery in forested Mediterranean landscapes. For. Ecol. Manage. 2012, 279, 121-127, doi:10.1016/j.foreco.2012.05.020.

15. Pausas, J.G. Changes in Fire and Climate in the Eastern Iberian Peninsula (Mediterranean Basin). Clim. Chang. 2004633 2004, 63, 337-350, doi:10.1023/B:CLIM.0000018508.94901.9C.

16. Doblas-Miranda, E.; Martínez-Vilalta, J.; Lloret, F.; Álvarez, A.; Ávila, A.; Bonet, F.J; Brotons, L.; Castro, J.; Curiel Yuste, J.; Díaz, M.; et al. Reassessing global change research priorities in mediterranean terrestrial ecosystems: How far have we come and where do we go from here? Glob. Ecol. Biogeogr. 2015, 24, 25-43, doi:10.1111/geb.12224.

17. Virgós, E. Relative value of riparian woodlands in landscapes with different forest cover for medium-sized Iberian. Biodivers. Conserv. 2001, 10, 1039-1049.

18. Riera, J.; Castell, C. Efectes dels incendis forestals recurrents sobre la distribució de dues espècies del Parc Natural del Garraf: el pi blanc (Pinus halepensis) i la savina (Juniperus phoenicea). Butlletí la Inst. Catalana d'Història Nat. 1997, 65, 105-116.

19. Baśnou, C.; Álvarez, E.; Bagaria, G.; Guardiola, M.; Isern, R.; Vicente, P.; Pino, J. Spatial patterns of land use changes across a mediterranean metropolitan landscape: Implications for biodiversity management. Environ. Manage. 2013, 52, 971-980, doi:10.1007/s00267-013-0150-5.

20. Ferreras, P.; DÍaz-Ruiz, F.; Monterroso, P. Improving mesocarnivore detectability with lures in camera-trapping studies. Wildl. Res. 2018, 45, 505-517, doi:10.1071/WR18037.

21. Molina-Vacas, G.; Bonet-Arbolí, V.; Rodríguez-Teijeiro, J.D. Habitat selection of two medium-sized carnivores in an isolated and highly anthropogenic Mediterranean park: The importance of riverbank vegetation. Ital. J. Zool. 2012, 79, 128-135, doi:10.1080/11250003.2011.620637.

22. Schuette, P.; Wagner, A.P.; Wagner, M.E.; Creel, S. Occupancy patterns and niche partitioning within a diverse carnivore community exposed to anthropogenic pressures. Biol. Conserv. 2013, 158, 301-312, doi:10.1016/j.biocon.2012.08.008.

23. Barrull, J.; Mate, I.; Ruiz-Olmo, J.; Casanovas, J.G.; Gosàlbez, J.; Salicrú, M. Factors and mechanisms that explain coexistence in a Mediterranean carnivore assemblage: An integrated study based on camera trapping and diet. Mamm. Biol. 2014, 79, 123-131, doi:10.1016/j.mambio.2013.11.004. 
24. Recio, M.R.; Arija, C.M.; Cabezas-Díaz, S.; Virgós, E. Changes in Mediterranean mesocarnivore communities along urban and ex-urban gradients. Curr. Zool. 2015, 61, 793-801, doi:10.1093/czoolo/61.5.793.

25. Ferreras, P.; Díaz-Ruiz, F.; Alves, P.C.; Monterroso, P. Optimizing camera-trapping protocols for characterizing mesocarnivore communities in south-western Europe. J. Zool. 2017, 301, 23-31, doi:10.1111/jzo.12386.

26. Requena-Mullor, J.M.; López, E.; Castro, A.J.; Cabello, J.; Virgós, E.; González-Miras, E.; Castro, H. Modeling spatial distribution of European badger in arid landscapes: an ecosystem functioning approach. Landsc. Ecol. 2014, 29, 843-855, doi:10.1007/s10980-014-0020-4.

27. Grajera, J.; Vilella, M.; Torre, I. A pilot study of the use of dry dog food as an alternative attractant in mesocarnivore studies. Mammalia 2021, 85, 422-427, doi:10.1515/mammalia-2020-0056.

28. Torre, I.; Arrizabalaga, A.; Freixas, L.; Ribas, A.; Flaquer, C.; Diaz, M. Using scats of a generalist carnivore as a tool to monitor small mammal communities in Mediterranean habitats. Basic Appl. Ecol. 2013, 14, 155-164, doi:10.1016/j.baae.2013.01.005.

29. Pita, R.; Mira, A.; Moreira, F.; Morgado, R.; Beja, P. Influence of landscape characteristics on carnivore diversity and abundance in Mediterranean farmland. Agric. Ecosyst. Environ. 2009, 132, 57-65, doi:10.1016/j.agee.2009.02.008.

30. O'Hara, R.B.; Kotze, D.J. Do not log-transform count data. Methods Ecol. Evol. 2010, 1, 118-122, doi:10.1111/j.2041210X.2010.00021.x.

31. Nakagawa, S.; Schielzeth, H. A general and simple method for obtaining R2 from generalized linear mixedeffects models. Methods Ecol. Evol. 2013, 4, 133-142.

32. Barton, K. Package “MuMIn” Multi-Model Inference 2020.

33. Bates, D.; Mächler, M.; Bolker, B.M.; Walker, S.C. Fitting linear mixed-effects models using lme4. J. Stat. Softw. 2015, 67, doi:10.18637/jss.v067.i01.

34. Mackenzie, D.L.; Nichols, J.D.; Royle, J.A.; Pollock, K.H.; Bailey, L.L.; Hines, J.E. Occupancy Estimation and Modeling Inferring Patterns and Dynamics of Species Occurrence; Elsevier: London, UK, 2018;

35. Mackenzie, D.I.; Nichols, J.D.; Lachman, G.B.; Droege, S.; Royle, J.A.; Langtimm, C.A. Estimating site occupancy rates when detection probabilities are less than one. Ecology 2002, 83, 2248-2255.

36. MacKenzie, D.I. PRESENCE User Manual 2012, 1-78.

37. Pita, R.; Morgado, R.; Moreira, F.; Mira, A.; Beja, P. Roads, forestry plantations and hedgerows affect badger occupancy in intensive Mediterranean farmland. Agric. Ecosyst. Environ. 2020, 289, doi:10.1016/j.agee.2019.106721.

38. Virgós, E.; Romero, T.; Mangas, J.G. Factors determining" gaps" in the distribution of a small carnivore, the common genet (Genetta genetta), in central Spain. Can. J. Zool. 2001, 79, 1544-1551.

39. Ferreira-Rodriguez, N.; Pombal, M.A. Bait effectiveness in camera trap studies in the Iberian Peninsula. MAMMAL Res. 2019, 64, 155-164, doi:10.1007/s13364-018-00414-1.

40. Hegglin, D.; Bontadina, F.; Gloor, S.; Romer, J.; Müller, U.; Breitenmoser, U.; Deplazes, P. BAITING RED FOXES IN AN URBAN AREA : A CAMERA TRAP STUDY. J. Wildl. Manage. 2002, 68, 1010-1017.

41. Mangas, J.G.; Lozano, J.; Cabezas-Díaz, S.; Virgós, E. The priority value of scrubland habitats for carnivore conservation in Mediterranean ecosystems. Biodivers. Conserv. 2008, 17, 43-51, doi:10.1007/s10531-007-9229-8.

42. Š́lek, M.; Červinka, J.; Pavluvčík, P.; Poláková, S.; Tkadlec, E. Forest-edge utilization by carnivores in relation to local and landscape habitat characteristics in central European farmland. Mamm. Biol. 2014, 79, 176-182, doi:10.1016/j.mambio.2013.08.009.

43. Chapron, G.; Kaczensky, P.; Linnell, J.D.C.; Von Arx, M.; Huber, D.; Andrén, H.; López-Bao, J.V.; Adamec, M.; 
Álvares, F.; Anders, O.; et al. Recovery of large carnivores in Europe's modern human-dominated landscapes. Science (80-. ). 2014, 346, 1517-1519, doi:10.1126/science.1257553.

44. Clinchy, M.; Zanette, L.Y.; Roberts, D.; Suraci, J.P.; Buesching, C.D.; Newman, C.; Macdonald, D.W. Fear of the human "super predator" far exceeds the fear of large carnivores in a model mesocarnivore. Behav. Ecol. 2016, 27, 1826-1832, doi:10.1093/beheco/arw117.

45. Suraci, J.P.; Smith, J.A.; Clinchy, M.; Zanette, L.Y.; Wilmers, C.C. Humans, but not their dogs, displace pumas from their kills: An experimental approach. Sci. Rep. 2019, 9, doi:10.1038/s41598-019-48742-9.

46. Vanak, A.T.; Gompper, M.E. Dogs Canis familiaris as carnivores: their role and function in intraguild competition. Mamm. Rev. 2009, 39, 265-283, doi:10.1111/J.1365-2907.2009.00148.X.

47. Vilella, M.; Ferrandiz-Rovira, M.; Sayol, F. Coexistence of predators in time: Effects of season and prey availability on species activity within a Mediterranean carnivore guild. Ecol. Evol. 2020, 10, 11408-11422, doi:10.1002/ece3.6778.

48. Carricondo-Sanchez, D.; Odden, M.; Kulkarni, A.; Vanak, A.T. Scale-dependent strategies for coexistence of mesocarnivores in human-dominated landscapes. Biotropica 2019, 51, 781-791, doi:10.1111/btp.12705.

49. Torre, I.; Díaz, M. Small mammal abundance in Mediterranean post-fire habitats: a role for predators? Acta Oecologica 2004, 25, 137-142, doi:10.1016/j.actao.2003.10.007.

50. Oro, D.; Sanz-Aguilar, A.; Carbonell, F.; Grajera, J.; Torre, I. Multi-species prey dynamics influences local survival in resident and wintering generalist predators. Oecologia (Berlin) 2021, 00, 00, doi:10.1007/s00442-02105042-2 POPULATION.

51. Torre, I.; Jaime-González, C.; Díaz, M. Habitat Suitability for Small Mammals in Mediterranean Landscapes: How and Why Shrubs Matter. Sustain. 2022, Vol. 14, Page 1562 2022, 14, 1562, doi:10.3390/SU14031562.

52. Torre, I.; Raspall, A.; Arrizabalaga, A.; Díaz, M. SEMICE: An unbiased and powerful monitoring protocol for small mammals in the Mediterranean Region. Mamm. Biol. 2018, 88, 161-167, doi:10.1016/j.mambio.2017.10.009.

53. Goncalves, P.; Alcobia, S.; Simoes, L.; Santos-Reis, M. Effects of management options on mammal richness in a Mediterranean agro-silvo-pastoral system. Agrofor. Syst. 2012, 85, 383-395, doi:10.1007/s10457-011-9439-7.

54. Palomares, F.; Delibes, M. COMPARATIVE ECOLOGY OF THE COMMON GENET GENETTA-GENETTA L. AND THE EGYPTIAN MONGOOSE HERPESTES-ICHNEUMON L. MAMMALIA VIVERRIDAE AT DONANA SW IBERIAN PENINSULA. Bol. la Real Soc. Esp. Hist. Nat. Secc. Biol. 1991, 87, 257-266.

55. Palomares, F.; Delibes, M. Predation upon European Rabbits and Their Use of Open and Closed Patches in Mediterranean Habitats. Oikos 1997, 80, 407, doi:10.2307/3546609.

56. López-Bao, J. V.; González-Varo, J.P. Frugivory and Spatial Patterns of Seed Deposition by Carnivorous Mammals in Anthropogenic Landscapes: A Multi-Scale Approach. PLoS One 2011, 6, e14569, doi:10.1371/JOURNAL.PONE.0014569.

57. Escribano-Avila, G.; Calviño-Cancela, M.; Pías, B.; Virgós, E.; Valladares, F.; Escudero, A. Diverse guilds provide complementary dispersal services in a woodland expansion process after land abandonment. J. Appl. Ecol. 2014, 51, 1701-1711, doi:10.1111/1365-2664.12340.

58. Valladares, F.; Benavides, R.; Rabasa, S.G.; Díaz, M.; Pausas, J.G.; Paula, S.; Simonson, W.D. Global change and Mediterranean forests: current impacts and potential responses. In Forests and Global Change; Cambridge University Press, 2014; pp. 47-76. 
Table 1. Generalized Linear Mixed Models (GLMM) with Poisson error distribution selected for each response variable (they are simple counts, contacts, except for the first one, richness). Transect and camera position are applied as nested random factors in all the models. The selected model corresponds to the one with the highest conditional pseudo- $R^{2}$ (Pseudo- $R^{2}$ c.) among the models with $\triangle A I C c<2$. Four explanatory variables: Attractant (factor with two levels: presence, absence - taken as reference), Season 3 (factor with two levels: winter, summer - taken as reference) and the two principal components PC1 and PC2 (continuous covariates) summarising vegetation structure. 4 Model $\beta$ coefficients and, in brackets, their standard error. In all cases, $n=127$. The same models with binomial and negative binomial error distribution showed similar 5 results (not shown).

\begin{tabular}{|c|c|c|c|c|c|c|c|c|}
\hline & $\begin{array}{l}\text { Wild carnivores } \\
\text { (richness) }\end{array}$ & Wild carnivores & $\begin{array}{l}\text { Vulpes } \\
\text { vulpes }\end{array}$ & $\begin{array}{l}\text { Martes } \\
\text { foina }\end{array}$ & $\begin{array}{l}\text { Meles } \\
\text { meles }\end{array}$ & Genetta genetta & Canis familiaris & $\begin{array}{l}\text { Felis } \\
\text { catus }\end{array}$ \\
\hline (Intercept) & $\begin{array}{l}-2.04^{* * *} \\
(0.46)\end{array}$ & $\begin{array}{l}-1.74^{* * *} \\
(0.39)\end{array}$ & $\begin{array}{l}-2.61^{* * *} \\
(0.54)\end{array}$ & $\begin{array}{l}-4.51^{* * *} \\
(1.10)\end{array}$ & $\begin{array}{l}-2.52^{* * *} \\
(0.53)\end{array}$ & $\begin{array}{l}-6.76^{* *} \\
(2.13)\end{array}$ & $\begin{array}{l}-2.70^{* * *} \\
(0.52)\end{array}$ & $\begin{array}{l}-4.63^{* *} \\
(1.56)\end{array}$ \\
\hline Attractant & $\begin{array}{l}1.91^{* * *} \\
(0.49)\end{array}$ & $\begin{array}{l}2.29^{* * *} \\
(0.41)\end{array}$ & $\begin{array}{l}2.35^{* * *} \\
(0.54)\end{array}$ & $\begin{array}{l}3.16^{* *} \\
(1.12)\end{array}$ & - & $\begin{array}{l}2.42^{*} \\
(1.13)\end{array}$ & $\begin{array}{l}0.88^{* *} \\
(0.31)\end{array}$ & - \\
\hline Season & $\begin{array}{l}1.48^{* *} \\
(0.49)\end{array}$ & $\begin{array}{l}1.28^{* *} \\
(0.42)\end{array}$ & $\begin{array}{l}1.34^{*} \\
(0.56)\end{array}$ & $\begin{array}{l}1.90 \\
(1.17)\end{array}$ & - & $\begin{array}{l}1.16 \\
(0.91)\end{array}$ & $\begin{array}{l}0.13 \\
(0.33)\end{array}$ & $\begin{array}{l}0.99^{*} \\
(0.46)\end{array}$ \\
\hline PC1 & $\begin{array}{l}0.29^{*} \\
(0.14)\end{array}$ & $\begin{array}{l}0.30^{*} \\
(0.13)\end{array}$ & $\begin{array}{l}-0.02 \\
(0.19)\end{array}$ & - & - & - & $\begin{array}{l}-0.30 \\
(0.19)\end{array}$ & - \\
\hline PC2 & $\begin{array}{l}0.29^{*} \\
(0.14)\end{array}$ & $\begin{array}{l}0.37^{*} \\
(0.16)\end{array}$ & $\begin{array}{l}0.09 \\
(0.25)\end{array}$ & $\begin{array}{l}0.62^{*} \\
(0.28)\end{array}$ & - & - & $\begin{array}{l}0.92^{*} \\
(0.42)\end{array}$ & $\begin{array}{l}1.49^{*} \\
(0.65)\end{array}$ \\
\hline Attractant :Season & $\begin{array}{l}-1.47^{* *} \\
(0.56)\end{array}$ & $\begin{array}{l}-1.50^{* *} \\
(0.56)\end{array}$ & $\begin{array}{l}-1.89^{* *} \\
(0.72)\end{array}$ & $\begin{array}{l}-2.11 \\
(1.43)\end{array}$ & - & - & - & - \\
\hline Attractant :PC1 & $\begin{array}{l}-0.22 \\
(0.16)\end{array}$ & $\begin{array}{l}-0.32^{* *} \\
(0.12)\end{array}$ & $\begin{array}{l}-0.27 \\
(0.13)\end{array}$ & - & - & - & - & - \\
\hline Attractant :PC2 & - & - & - & - & - & - & - & - \\
\hline Season:PC1 & - & - & - & - & - & - & - & - \\
\hline Season:PC2 & - & - & - & - & - & - & $\begin{array}{l}-0.75^{*} \\
(0.34)\end{array}$ & $\begin{array}{l}-0.86 \\
(0.44)\end{array}$ \\
\hline PC1:PC2 & - & - & $\begin{array}{l}-0.49^{* *} \\
(0.17)\end{array}$ & - & - & - & - & - \\
\hline $\mathrm{AICc}$ & 262.40 & 392.18 & 284.40 & 185.16 & 135.82 & 71.87 & 194.54 & 145.04 \\
\hline$\triangle \mathrm{AICc}$ & 0.18 & 1.36 & 1.10 & 0.90 & 0.00 & 0.27 & 1.94 & 0.00 \\
\hline AICc Weight & 0.17 & 0.24 & 0.10 & 0.21 & 0.18 & 0.24 & 0.05 & 0.73 \\
\hline Pseudo-R² m. & 0.36 & 0.46 & 0.40 & 0.30 & 0.00 & 0.15 & 0.17 & 0.17 \\
\hline
\end{tabular}


Pseudo- $R^{2} \mathrm{c}$.

0.39

0.70

0.63

0.60

0.28

0.56

0.53

0.99

${ }^{* * *} \mathrm{p}<0.001,{ }^{* *} \mathrm{p}<0.01,{ }^{*} \mathrm{p}<0.05$

9

Preprints (wruw.preprints.org) | NOT PEER-REVIEWED | Posted: 7 February 2022

10


Table S1. Multi-season occupancy models for the wild mesocarnivore species. Only significant models (DeltaAIC $<2$ ) are shown, and null models $(\psi(\cdot), \gamma(\cdot), p(\cdot))$ shown for comparison.

\begin{tabular}{c|llllll}
\multicolumn{1}{c}{ MPECIES } & \multicolumn{1}{c}{ MODEL } & AIC & DELTAAIC & $\begin{array}{l}\text { AICC } \\
\text { WEIGHT }\end{array}$ & $\begin{array}{l}\text { MODEL } \\
\text { LIKELIHOOD }\end{array}$ \\
\hline \multirow{2}{*}{ GENET } & $\psi(\cdot), \gamma(\cdot), p($ bait $)$ & 96.05 & 0 & 0.38 & 1.00 & NO.PAR. \\
& $\psi(P C 2), \gamma(\cdot), p($ bait $)$ & 97.09 & 1.04 & 0.23 & 0.59 & 5 \\
& $\psi(P C 1), \gamma(\cdot), p($ bait $)$ & 97.49 & 1.44 & 0.18 & 0.49 & 5 \\
& $\psi(\cdot), \gamma(\cdot), p(\cdot)$ & 101.98 & 5.93 & 0.02 & 0.05 & 3 \\
\hline STONE & $\psi(P C 2), \gamma(\cdot), \varepsilon(\cdot), p($ bait $)$ & 220.44 & 0 & 0.83 & 1.00 & 6 \\
MARTEN & $\psi(\cdot), \gamma(\cdot), p(\cdot)$ & 235.53 & 15.09 & 0.00 & 0.00 & 3 \\
\hline RED FOX & $\psi(P C 1), \gamma(\cdot), p($ bait $)$ & 356.07 & 0 & 0.29 & 1.00 & 5 \\
& $\psi(\cdot), \gamma(\cdot), p($ bait $)$ & 356.09 & 0.02 & 0.29 & 0.99 & 4 \\
& $\psi(P C 2), \gamma(\cdot), p($ bait $)$ & 356.66 & 0.59 & 0.22 & 0.74 & 5 \\
\hline BADGER & $\psi(\cdot), \gamma(\cdot), p(\cdot)$ & 359.71 & 3.64 & 0.05 & 0.16 \\
\hline
\end{tabular}


Figure S1. Cumulative detection probabilities of the four wild mesocarnivores along field surveys (secondary sampling occasions) in baited (dark symbols) and non-baited (open symbols) camera stations. Red fox (circle), stone marten (triangle), genet (square), and badger (diamond).

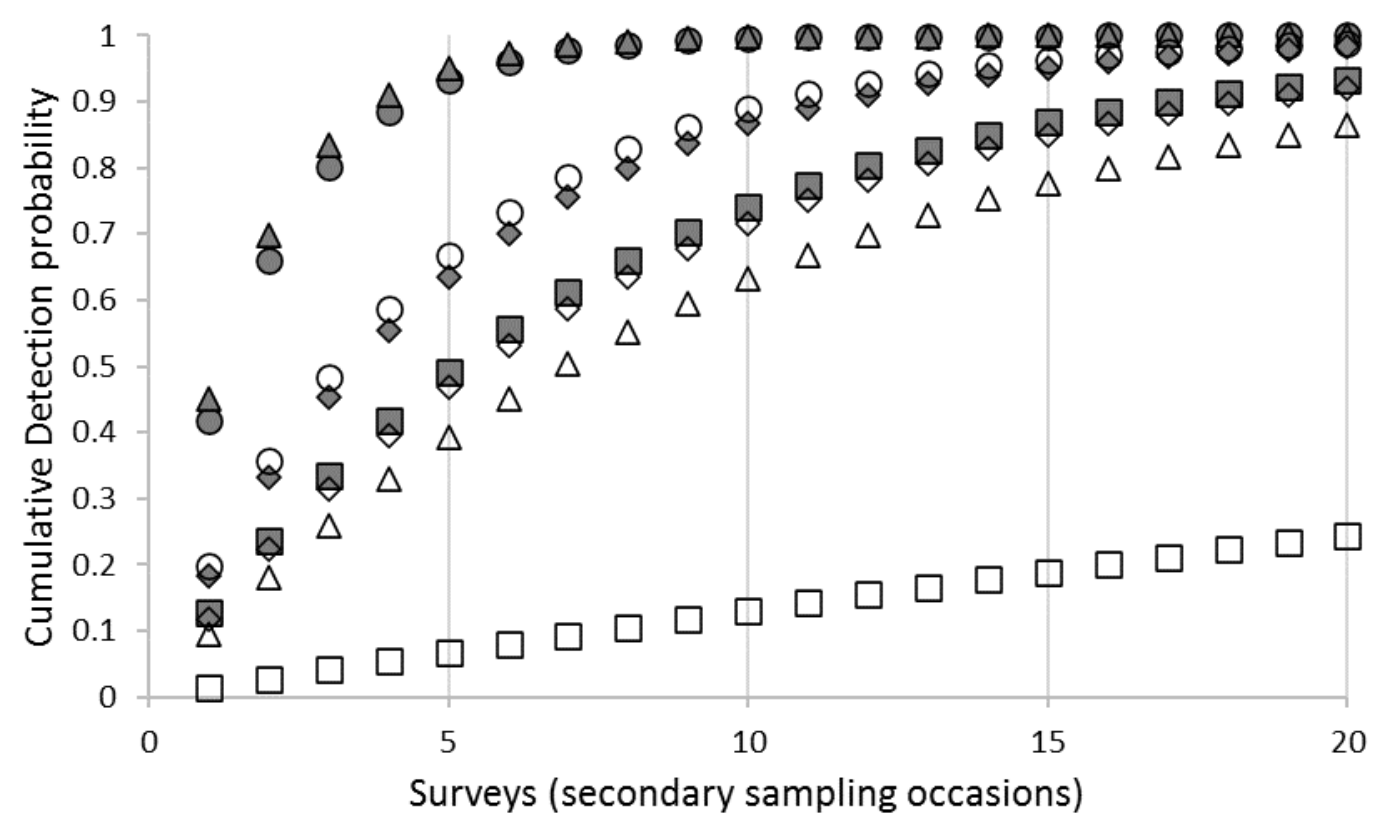

